\title{
DIFERENTES NÍVEIS DE BETAIINA NA RAÇÃO DE SUÍNOS SOBRE A ESTRUTURA E ULTRA-ESTRUTURA DA MUCOSA INTESTINAL
}

\section{DIFFERENT LEVELS OF BETAINE IN RATION OF SWINE ON STRUCTURE AND ULTRA-STRUCTURE OF INTESTINAL MUCOUS}

\author{
Paulo Roberto Ribeiro ${ }^{1}$ \\ Rodolfo Nascimento Kronka² \\ Maria Cristina Thomaz ${ }^{2}$ \\ Melissa Izabel Hannas ${ }^{3}$ \\ Fernanda Marcussi Tucci ${ }^{4}$ \\ Antônio João Scandolera ${ }^{5}$ \\ Fábio Enrique Lemos Budiño $6^{*}$
}

\author{
${ }^{1}$ Instituto Federal de Educação Ciência e Tecnologia do Triângulo Mineiro, Uberlândia, MG, Brasil. \\ 'Universidade Estadual Paulista, Faculdade de Ciências Agrárias e Veterinárias, Jaboticabal, SP, Brasil. \\ 3Universidade Federal de Viçosa, Viçosa, MG, Brasil \\ ${ }^{4}$ Ministério da Agricultura, Pecuária e Abastecimento, Brasília DF, Brasil \\ ${ }^{5}$ Universidade Federal do Paraná, Curitiba, PR, Brasil. \\ ${ }^{6}$ Instituto de Zootecnia, Agência Paulista de Tecnologia dos Agronegócios, Nova Odessa, SP, Brasil. \\ *Autor para correspondência - fbudino@iz.sp.gov.br
}

\section{Resumo}

Foram avaliados os efeitos da adição de diferentes níveis de betaína $(0,0 \%, 0,1 \%, 0,2 \%, 0,3 \%)$ sobre a morfologia do intestino delgado. Foram utilizados 52 leitões desmamados aos 23 dias de idade e peso médio de $5,4 \mathrm{~kg}$, quatro níveis de betaína e cinco épocas de abate. Foram efetuados cinco abates, com intervalos de três dias, considerando o dia da desmama como o dia zero. Foram avaliadas altura de vilosidade e profundidade de criptas. Foram observadas diferenças significativas $(\mathrm{P}<0,05)$ entre os tratamentos para altura das vilosidades no duodeno e para profundidade de criptas do íleo. Em relação aos dias pós-desmama, ocorreram diferenças significativas $(\mathrm{P}<0,05)$ para altura de vilosidades e profundidade de criptas nos três segmentos intestinais analisados.

Palavras-chave: elétron-micrografias; leitão; nutrição; vilosidade.

\begin{abstract}
We evaluated the effects of increasing levels of betaine $(0.0 \%, 0.1 \%, 0.2 \%, 0.3 \%)$ on small intestine structure. Fifty-two weaned piglets at 23 days of age and average weight of $5.4 \mathrm{~kg}$ were used. We studied four betaine levels and five slaughtered times with three days of interval, considering the weaning day as the initial day (zero day). We evaluated villi height and crypt depth. We observed significant differences $(\mathrm{P}<0.05)$ among treatments for villi height in duodenum and for crypt depth in ileum. Regarding post-weaning days, significant differences $(\mathrm{P}<0.05)$ in villi height and crypt depth occurred in the three intestinal segments analyzed.
\end{abstract}

Keywords: electron micrograph; nutrition; piglet; villous.

Enviado em: 23 outubro 2012

Aceito em: 08 outubro 2015 


\section{Introdução}

As propriedades químicas específicas da betaína são devidas a sua estrutura bipolar e a seus radicais metila $\left(\mathrm{CH}_{3}\right)$ quimicamente reativos, os quais podem, quando doados, participar de reações catalisadas por enzimas. A betaína é quimicamente estável, tolerando temperaturas de até $200^{\circ} \mathrm{C}$. Ela está presente em todos os organismos vivos em quantidades variáveis. Enquanto a maioria dos organismos (vegetais ou animais) a utiliza como fonte de grupos metila em reações de metilação, poucos conseguem acumulá-la em altas concentrações, como, por exemplo, algumas plantas pertencentes à família das Chenopodiaceae, beterraba-açucareira (Beta vulgaris var. esculenta) ${ }^{(1)}$.

A betaína atua ao mesmo tempo como osmolito, diminuindo a demanda energética do suíno para manter uma adequada hidratação celular, bem como o equilíbrio iônico, e como doadora de grupos metil. Esta forma de atuar da betaína supõe economia de energia de manutenção para o suíno além de uma menor necessidade de doadores de grupos metil, tais como a metionina e a colina ${ }^{(2)}$.

A betaína pode ser sintetizada a partir da colina na mitocôndria, porém o nível de síntese não é suficientemente alto para responder às necessidades orgânicas variáveis de betaína, especialmente sob estresse. Desta forma, a suplementação da betaína na ração pode conduzir a melhorias no desempenho animal, devido a sua capacidade de doar radicais metil ${ }^{(3)}$.

Há evidências de que a betaína pode melhorar o desenvolvimento e a função intestinal. A presença da betaína no lúmen intestinal resulta em melhor capacidade absortiva e promove alterações na estrutura deste epitélio ${ }^{(4)}$. Fernandez-Figares et al. ${ }^{(5)}$ demonstraram que a suplementação com betaína $(0,125 \%)$ aumentou o peso do intestino delgado de leitões, embora em doses mais elevadas tenha ocorrido diminuição do peso deste órgão. De acordo com $\mathrm{Xu}$ e $\mathrm{Yu}^{(6)}$, há um aumento da altura das vilosidades no duodeno de leitões desmamados, sendo os vilos mais uniformes quando os animais são suplementados com betaína.

Este trabalho teve como objetivo avaliar a adição de diferentes níveis de betaína na dieta de leitões desmamados sobre a estrutura e a ultra-estrutura intestinal.

\section{Material e Métodos}

O experimento foi conduzido de 07 de fevereiro a 20 de março de 2000. Foram utilizados 64 leitões desmamados aos 23 dias de idade com peso médio de 5,4 kg, alojados em galpão de creche, em baias de alvenaria suspensas $(1,10 \mathrm{~m} \times 2,00 \mathrm{~m})$, com piso ripado de plástico, bebedouros em nível e comedouro de alvenaria, sendo distribuídos em quatro dietas experimentais (isoenergéticas e isoprotéicas) formuladas de forma a atender às exigências nutricionais dos suínos baseadas nas tabelas do $\mathrm{NRC}^{(7)}$ e suplementadas com betaína $(0,0 \%, 0,1 \%, 0,2 \%, 0,3 \%)$ de acordo com os tratamentos.

Quatro leitões, escolhidos ao acaso, foram utilizados na formação do grupo controle e abatidos no dia da desmama (Dia 0). Os 60 animais restantes foram submetidos aos tratamentos experimentais. Com intervalo de três dias (3, 6, 9 e 12 dias pós-desmama), três animais de cada tratamento, aleatoriamente, eram abatidos, respeitando-se as normas descritas no regulamento técnico de métodos de insensibilização para o abate ${ }^{(8)}$, para colheita do material a ser analisado. Logo em seguida, os animais foram eviscerados e amostras das porções proximais do duodeno, da porção intermédia do jejuno e da porção terminal do íleo foram coletadas para as análises de microscopia de luz e eletrônica de varredura.

Foram avaliadas a altura de vilosidades e a profundidade de criptas e amostras do intestino delgado foram elétron-micrografadas para visualização da ultra-estrutura intestinal.

Para a microscopia de luz, as amostras foram abertas pela borda mesentérica e estendidas pela serosa e, a seguir, fixadas em solução de Bouin por 24 horas. Após a fixação, as amostras foram lavadas em álcool etílico a $70^{\circ} \mathrm{GL}$ e, posteriormente, desidratadas em série crescente de álcoois, recortadas, diafanizadas em benzol e processadas, visando à inclusão orientada em parafina, de modo que se obtivessem cortes longitudinais da mucosa intestinal, que foram colocados em lâmina histológica, 
corados segundo a técnica da hematoxilina de Harris-eosina. Através da microscopia de luz, os cortes histológicos do duodeno, jejuno e íleo foram analisados morfológica e morfometricamente em um sistema analisador de imagens da Kontron Elektronik (Video Plan), com um aumento de 230 vezes, de modo que, em cada animal, foram medidas a altura $(\mu \mathrm{m})$ de 20 vilosidades e a profundidade $(\mu \mathrm{m})$ de 20 criptas, para o segmento intestinal coletado.

Para a microscopia eletrônica de varredura, amostras de aproximadamente $0,5 \mathrm{~cm}$ da porção proximal do duodeno, da porção média do jejuno e do íleo terminal foram coletadas de cada animal, abertas pela borda mesentérica e estendidas pela serosa e, a seguir, fixadas em solução tampão de glutaraldeído a $3 \%$, preparada a partir de uma solução de tampão fosfato de potássio $0,1 \mathrm{M} \mathrm{e} \mathrm{pH} \mathrm{7,4.} \mathrm{Em} \mathrm{seguida,} \mathrm{as}$ amostras foram pós-fixadas em solução de tetróxido de ósmio $2 \%$. Logo depois, foram desidratadas em séries crescentes de álcool etílico 30, 40, 50, 60, 70, 80, 90 e 100\%, com intervalos de 20 minutos. Então, elas foram secas em secador de ponto crítico Electron Microscopy Sciences 850, metalizadas a vácuo em DESK II, com liga de ouro-paládio, em comprimento de onda de $60 \mathrm{~nm} / 60 \mathrm{~s}^{(9)}$.

Em seguida, as amostras foram analisadas em microscópio eletrônico de varredura, modelo JSM 5410 JEOL, a $15 \mathrm{kV}$ com aumento de 150 vezes.

Foi utilizado o delineamento em blocos casualizados para controlar diferenças iniciais de peso, em esquema fatorial $4 \times 4+1$ (quatro dietas x quatro épocas de abate + um grupo controle) com três repetições, sendo que a unidade experimental foi constituída por um animal e as médias comparadas pelo teste de Tukey a $5 \%$ de probabilidade.

\section{Resultados e Discussão}

Quando se considerou dias $\mathrm{x}$ dietas, não houve diferença significativa $(\mathrm{P}>0,05)$ para esta interação, o que significa que, dentro dos diferentes dias de abate pós-desmama, os níveis de betaína não influenciaram a altura das vilosidades e a profundidades das criptas.

A altura da vilosidade do duodeno foi afetada $(\mathrm{P}<0.05)$ pela suplementação de betaína, sendo que animais recebendo $0,2 \%$ de betaína apresentaram vilosidades maiores, o que naturalmente pode proporcionar uma maior superfície de epitélio, já que quanto maior for o tamanho da vilosidade, maior a área absortiva ${ }^{(10)}$. Por outro lado, a profundidade de criptas foi afetada $(\mathrm{P}<0,05)$ somente no íleo (Tabela 1).

Tabela 1: Altura das vilosidades (AV) e profundidade de criptas (PC) da mucosa intestinal do duodeno, jejuno e íleo de leitões no período pós-desmama (0-12 dias) suplementados com níveis crescentes de betaína

\begin{tabular}{lllllll}
\hline & \multicolumn{2}{c}{ Duodeno } & \multicolumn{2}{c}{ Jejuno } & \multicolumn{2}{c}{ íleo } \\
Betaína (\%) & $\mathbf{A V}(\mu \mathrm{m})$ & $\mathbf{P C}(\mu \mathbf{m})$ & $\mathbf{A V}(\mu \mathbf{m})$ & PC $(\mu \mathbf{m})$ & $\mathbf{A V}(\mu \mathbf{m})$ & PC $(\mu \mathbf{m})$ \\
\hline 0,0 & $271,93 \mathrm{~b}$ & 168,67 & 319,07 & 181,07 & 301,11 & $182,93 \mathrm{~b}$ \\
0,1 & $272,93 \mathrm{ab}$ & 176,87 & 310,53 & 171,20 & 287,80 & $195,07 \mathrm{ab}$ \\
0,2 & $308,67 \mathrm{a}$ & 181,87 & 309,60 & 177,33 & 287,36 & $202,40 \mathrm{a}$ \\
0,3 & $275,93 \mathrm{ab}$ & 177,13 & 344,20 & 180,27 & 278,40 & $200,73 \mathrm{a}$ \\
CV $(\%)$ & 13,13 & 10,88 & 11,21 & 8,39 & 14,75 & 8,44 \\
\hline
\end{tabular}

${ }_{a, b}$ Médias com letras distintas, na mesma coluna, diferem $(\mathrm{P}<0,05)$ pelo teste de Tukey.

Quando considerado o período pós-desmama, a altura das vilosidades, para os três segmentos intestinais estudados (duodeno, jejuno e íleo) apresentou comportamento semelhante (Tabela 2), sendo que os maiores valores $(\mathrm{P}<0,05)$ foram encontrados no dia da desmama e, subsequentemente, ocorreu diminuição na altura das vilosidades no terceiro, sexto e nono dia pós-desmama, confirmando o que tem sido observado por diversos autores ${ }^{(11,12)}$.

No entanto, Marion et al. ${ }^{(10)}$ não observaram diferenças na altura das vilosidades do jejuno de leitões 
desmamados aos sete dias e abatidos aos 10, 14 e 21 dias de idade.

Relatos anteriores dão ênfase ao efeito negativo da mudança de uma alimentação líquida (leite materno) para sólida (ração) por ocasião da desmama dos leitões ${ }^{(13)}$. Os resultados obtidos neste estudo mostram que há um impacto negativo da mudança da alimentação na desmama dos leitões, sendo este caracterizado por uma redução no tamanho das vilosidades com uma posterior adaptação e consequente recuperação das mesmas por volta do $12^{\circ}$ dia pós-desmama. Estes resultados estão de acordo com aqueles obtidos por Budiño et al. ${ }^{(14)}$, embora estes autores tenham analisado a morfologia intestinal aos 14 dias pós-desmama.

Tabela 2: Altura das vilosidades (AV) e profundidade de criptas (PC) da mucosa intestinal do duodeno, jejuno e íleo de leitões no intervalo de 0-12 dias pós-desmama (DPD)

\begin{tabular}{lllllll}
\hline & \multicolumn{2}{c}{ Duodeno } & \multicolumn{2}{c}{ Jejuno } & \multicolumn{2}{c}{ Íleo } \\
DPD & AV $(\mu \mathrm{m})$ & PC $(\mu \mathrm{m})$ & AV $(\mu \mathrm{m})$ & PC $(\mu \mathbf{m})$ & AV $(\mu \mathrm{m})$ & PC $(\mu \mathbf{m})$ \\
\hline 0 & $365,33 \mathrm{a}$ & $149,67 \mathrm{c}$ & $455,00 \mathrm{a}$ & $153,00 \mathrm{c}$ & $339,43 \mathrm{a}$ & $167,00 \mathrm{~b}$ \\
3 & $271,25 \mathrm{~b}$ & $172,58 \mathrm{~b}$ & $272,17 \mathrm{c}$ & $172,08 \mathrm{~b}$ & $252,65 \mathrm{~b}$ & $181,08 \mathrm{~b}$ \\
6 & $239,33 \mathrm{~b}$ & $174,08 \mathrm{ab}$ & $264,67 \mathrm{c}$ & $184,92 \mathrm{ab}$ & $267,06 \mathrm{~b}$ & $203,67 \mathrm{a}$ \\
9 & $264,33 \mathrm{~b}$ & $187,92 \mathrm{ab}$ & $293,33 \mathrm{bc}$ & $184,75 \mathrm{ab}$ & $285,60 \mathrm{~b}$ & $212,83 \mathrm{a}$ \\
12 & $271,58 \mathrm{~b}$ & $196,42 \mathrm{a}$ & $319,08 \mathrm{~b}$ & $192,58 \mathrm{a}$ & $298,59 \mathrm{ab}$ & $211,83 \mathrm{a}$ \\
CV (\%) & 13,13 & 10,88 & 11,21 & 8,39 & 14,75 & 8,44 \\
\hline
\end{tabular}

a,b Médias com letras distintas na mesma coluna, diferem $(\mathrm{P}<0,05)$ pelo teste de Tukey.

A profundidade de criptas, que aumentou em função do tempo pós-desmama, foi afetada $(\mathrm{P}<0,05)$ pela idade dos animais (Tabela 2). Resultados semelhantes foram encontrados por Budiño et al. ${ }^{(14)}$, que verificaram aumento na profundidade das criptas aos sete dias pós-desmama. Maior valor de profundidade das criptas indica maior atividade proliferativa celular, para garantir adequada taxa de renovação epitelial e compensar as perdas na altura dos vilos ${ }^{(12)}$.

Os valores encontrados confirmam a redução da altura das vilosidades intestinais, visto que, com uma cripta mais profunda, demanda-se um maior tempo de migração e diferenciação da célula encontrada na submucosa do intestino delgado, proporcionando um menor número de enterócitos maduros no ápice da vilosidade ${ }^{(15)}$, comprometendo, assim, os processos absortivos.

Em avaliação subjetiva das elétron-micrografias (Figuras 1, 2 e 3 ), observou-se um comprometimento acentuado das vilosidades em função dos dias pós-desmama, independentemente dos tratamentos utilizados. De uma maneira geral, foi observado um aumento nas fusões entre as vilosidades adjacentes e deformações destas ao longo do epitélio intestinal a partir do terceiro dia pós-desmama, sendo que no décimo-segundo dia houve uma aparente recuperação das vilosidades, confirmando o comportamento observado para altura das mesmas. Estas observações de fusão entre vilosidades e deformações concordam com as de Scandolera et al. ${ }^{(16)}$.

Alterações morfológicas do trato intestinal de leitões, no período pós-desmama, que levam a redução na altura das vilosidades, fusões e deformidades de vilosidades podem contribuir para a redução da superfície digestiva e absortiva do intestino delgado. Assim, justifica-se a preconização de uma dieta diferenciada para os animais no período imediatamente pós-desmama. 

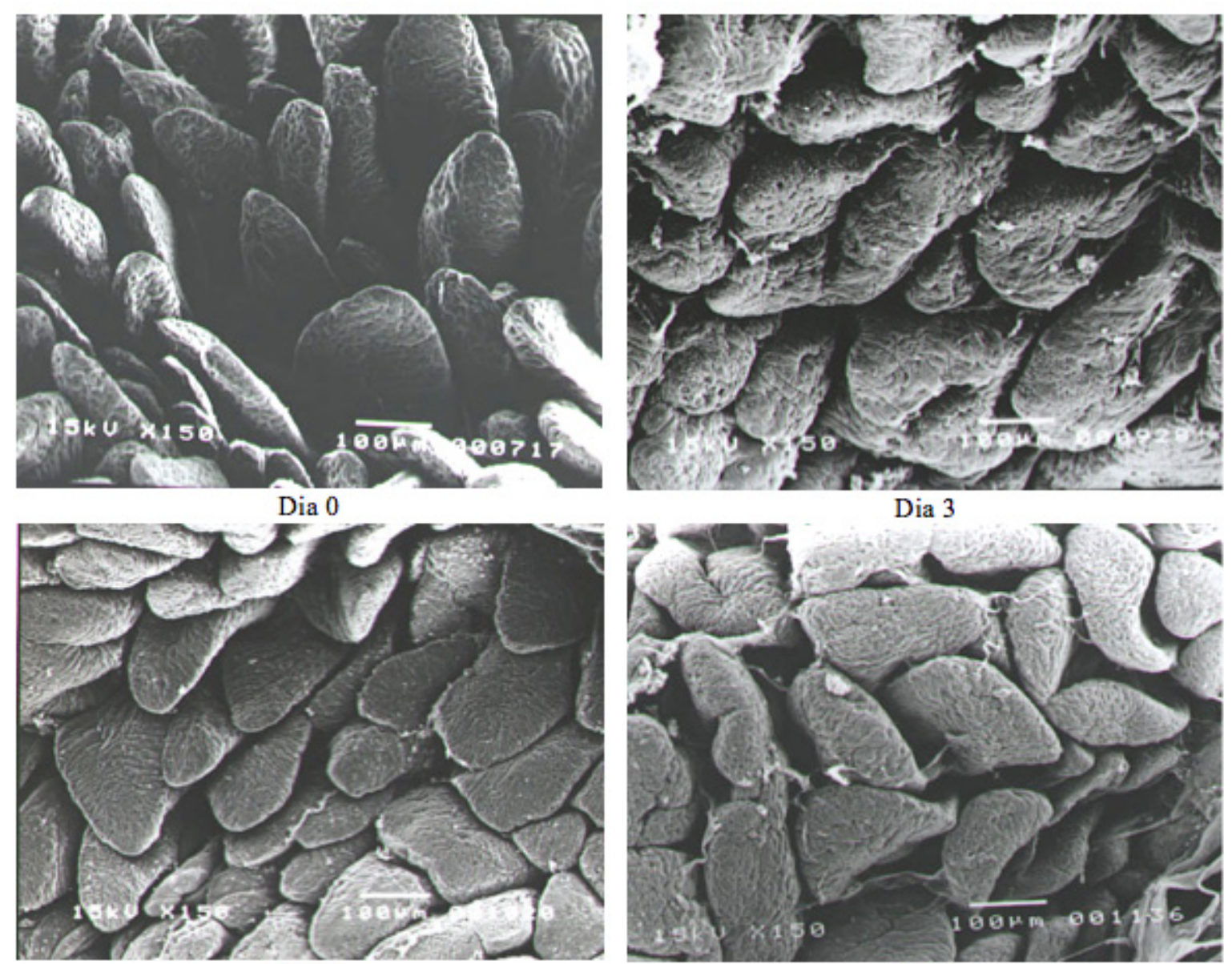

Dia 6

Dia 9

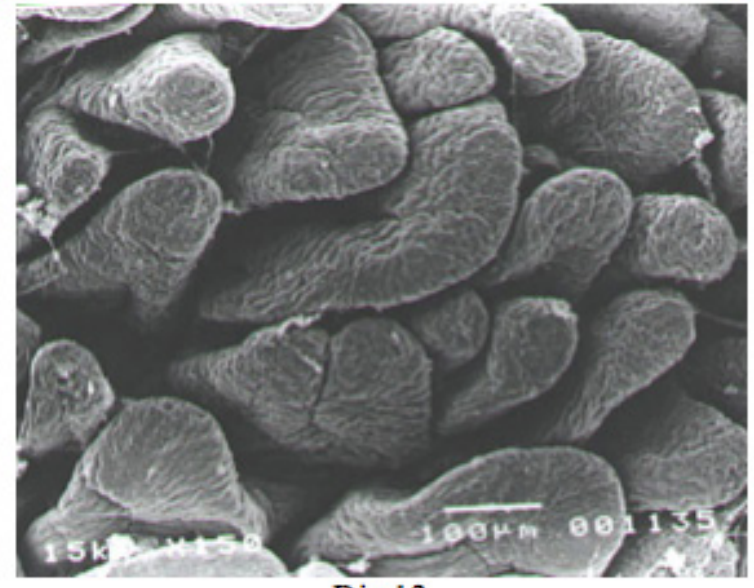

Dia 12

Figura 1. Elétron-micrografias (x150) das vilosidades do duodeno dos leitões nos diferentes dias pósdesmama. 

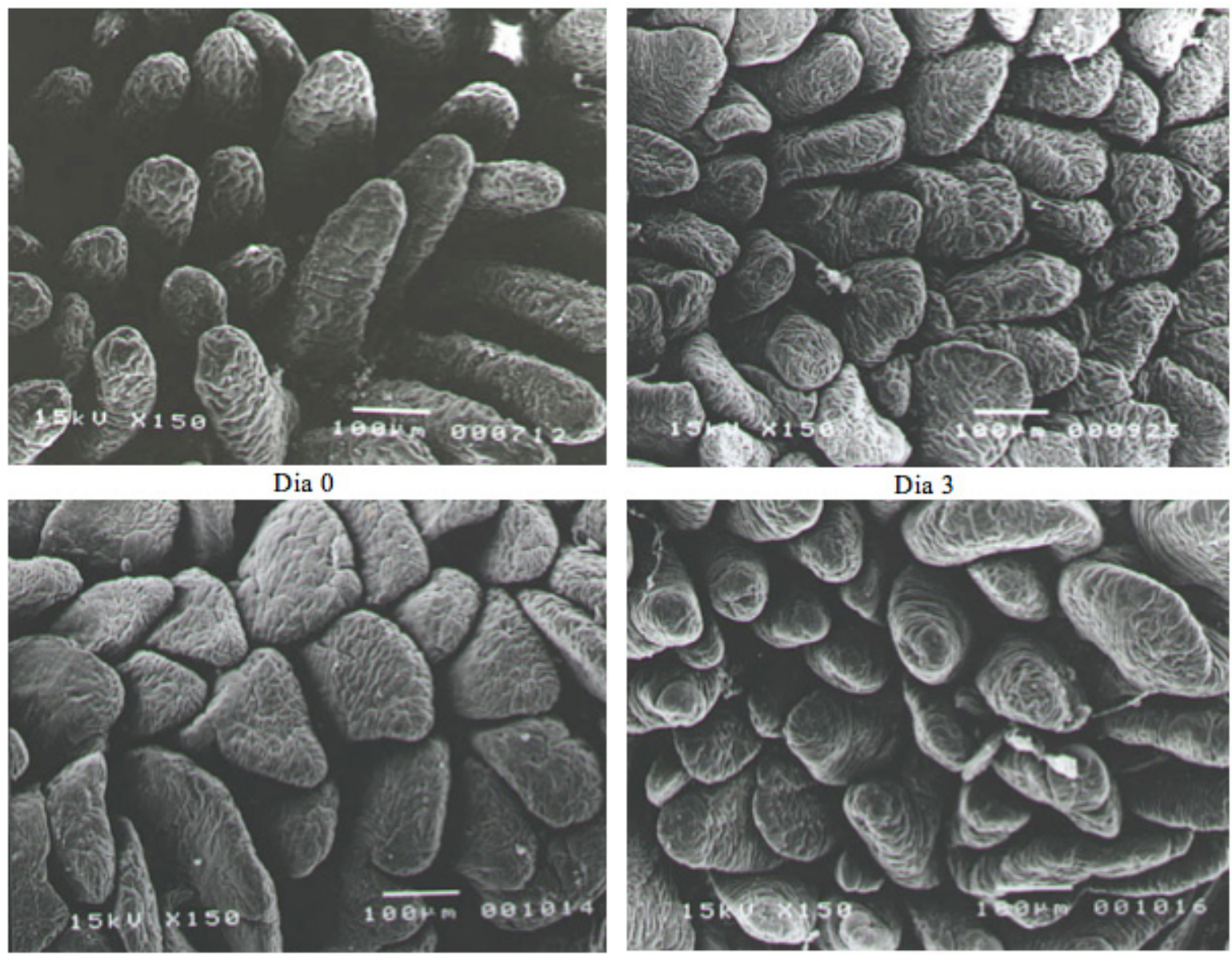

$$
\text { Dia } 3
$$
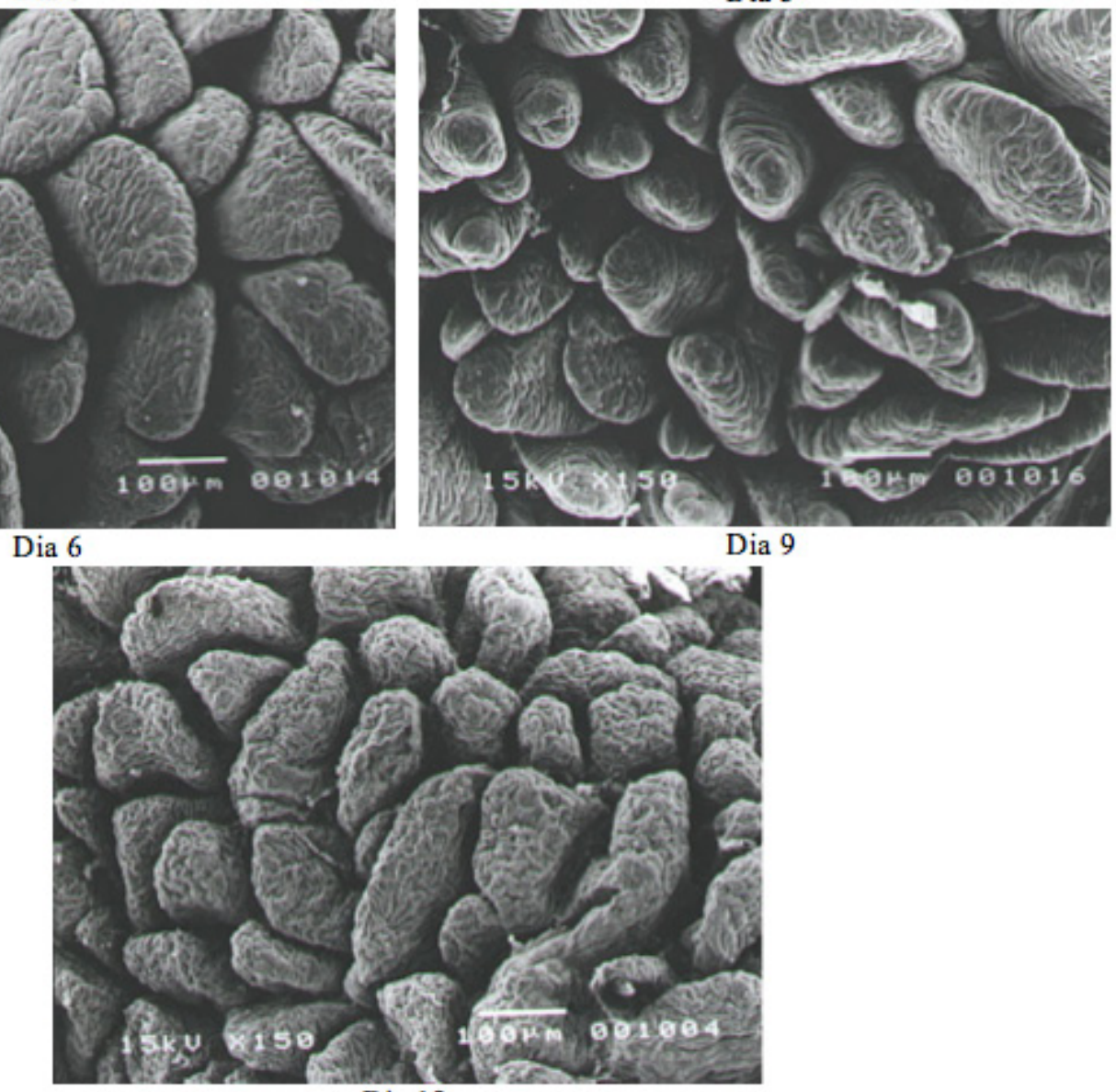

Dia 12

Figura 2. Elétron-micrografias (x150) das vilosidades do jejuno dos leitões nos diferentes dias pós-desmama 


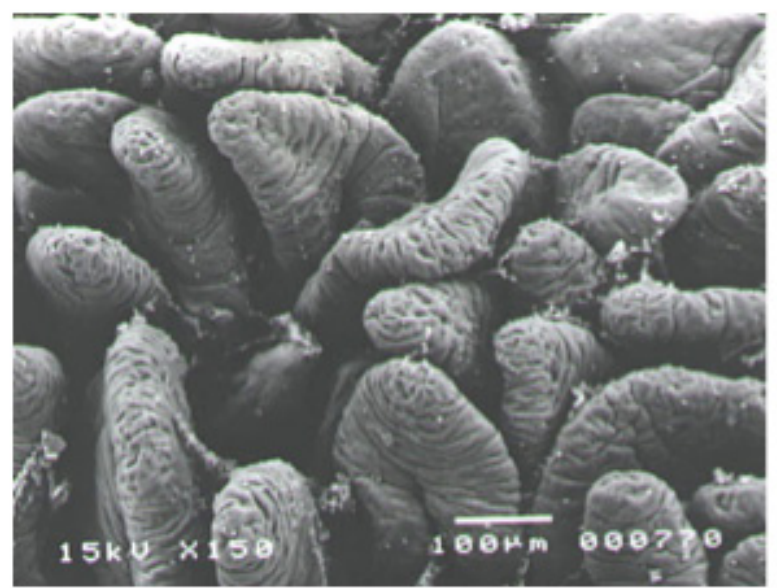

Dia 0

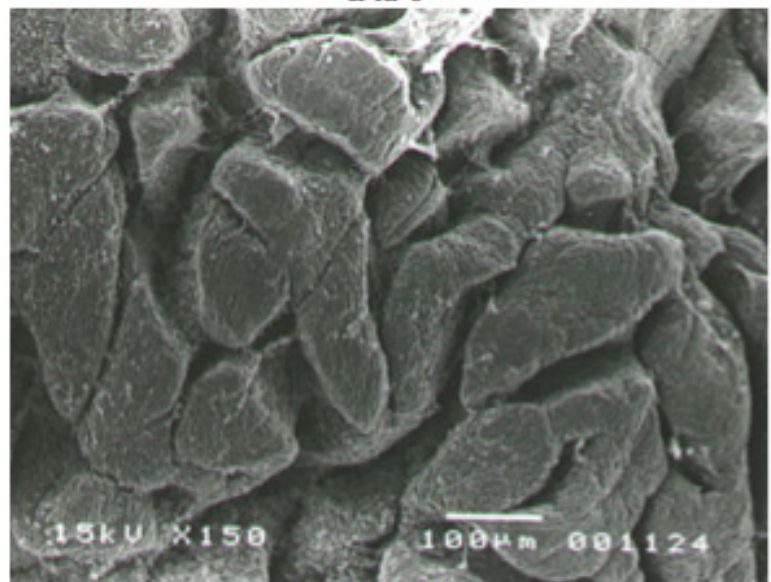

Dia 6

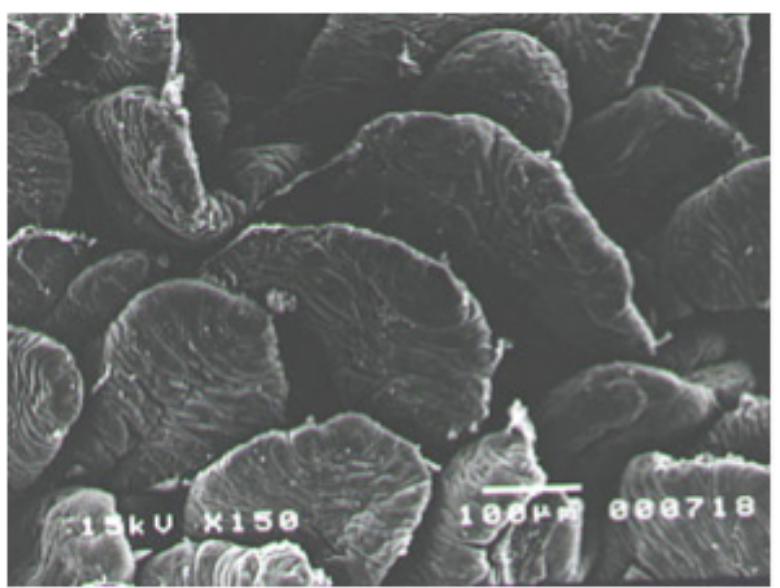

Dia 3

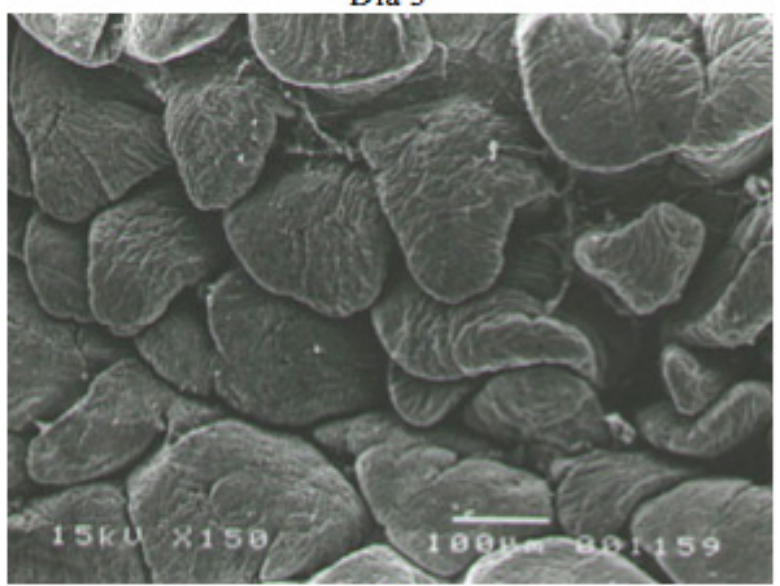

Dia 9

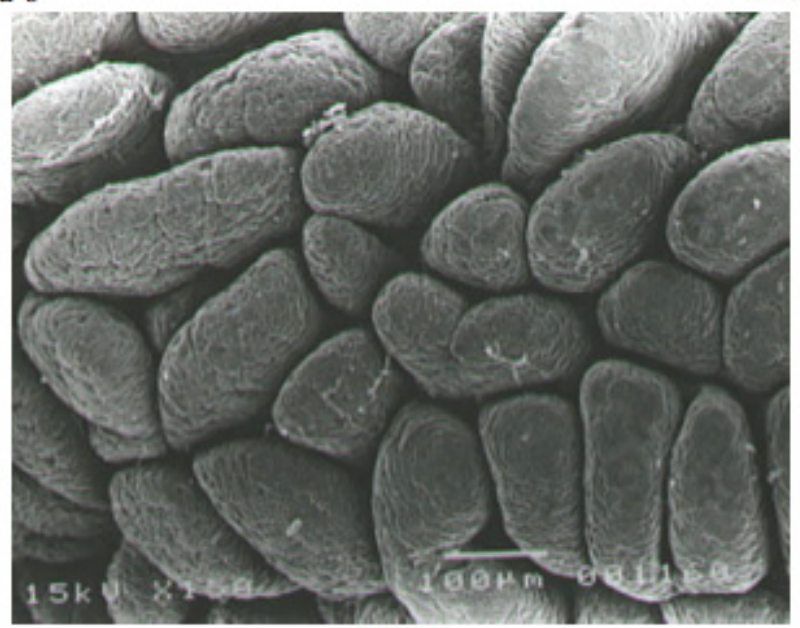

Dia 12

Figura 3. Elétron-micrografias (x150) das vilosidades do íleo dos leitões nos diferentes dias pós-desmama

\section{Conclusões}

No período pós-desmama, os animais submetidos à adição de $0,2 \%$ de betaína na dieta tiveram uma maior altura de vilosidades. A altura de vilosidades e a profundidade das criptas intestinais são afetadas em função da idade dos animais. 


\section{Referências}

1. Arantzamendi L, Duran R, Blanc A. Uso de Betafin en alimentacion porcina: donante de grupos metilo y osmolito. Anaporc. 2006;3:68-72.

2. Ribeiro PR, Kronka RN, Thomaz MC, Hannas MI, Tucci FM, Scandolera AJ, Budiño FEL. Diferentes níveis de betaína sobre incidência de diarreia, desempenho, características de carcaça e parâmetros sanguíneos de suínos. Braz J Vet Res Anim Sci. 2011;48(4):299-306.

3. Mercado AVV. La betaína en la nutrición porcina. Acontecer Porcino. 1995;8(16):4-6.

4. Kettunen H, Peuranen S, Tiihonen K. Betaine aids in the osmoregulation of duodenal epithelium of broiler chicks, and affects the movement of water across the small intestinal epithelium in vitro. Comp Biochem Phys. 2001; 129A:595-603.

5. Fernandez-Figares I, Wray-Cahen D, Steele NC, Campbell RG, Hall DD, Virtanen E, Caperna TJ. Effect of dietary betaine on nutrient utilization and partitioning in the young growing feed-restricted pig. J Anim Sci. 2002;80:421-428.

6. Xu ZR, Yu DY. Effect of betaine on digestive function of weaned piglets. Chinese J Vet Sci. 2000;20:201204.

7. NRC. Nutrient Requirement of Swine. 10. ed. Washington: National Academy Press, 1998. 189 p.

8. MAPA. Instrução Normativa $n^{\circ} .3$, de 07 de janeiro de 2000. Regulamento técnico de métodos de insensibilização para o abate humanitário de animais de açougue. S.D.A./M.A.A. Diário Oficial da União, Brasília, p.14-16, 24 de janeiro de 2000, Seção 1.1.1. Disponível em: $<$ http://www.agricultura.gov.br/arq editor/file/Ministerio/concursos/em andamento/instrucoes\%20normativas/INT\%20003\%2017\%2001\%20 2000\%20ABATE\%20HUMANIT\%25C1RIO\%20ANIMAIS\%20DE\%20ACOUGUE.doc $>$ Acesso em outubro de 2014

9. Ruiz MB. Microscopia óptica y electronica de Trichomonas Gallinae (Rivolta). Aspectos de la division y accion de la colchicina sobre su ultraestructura. Arch Zootec. 1977;26:349-390.

10. Marion J, Petersen YM, Romé V, Thomas F, Sangild PT, Le Dividich J, Le Huërou-Luron I. Early weaning stimulates intestinal brush border enzyme activities in piglets, mainly at the posttranscriptional level. J Pediatr Gastr Nutr. 2005;41:401-410.

11. Xu RJ, Wang F, Zhang SH. Postnatal adaptation of the gastrointestinal tract in neonatal pigs: a possible role of milk-borne growth factors. Livest Prod Sci. 2000;66:95-107.

12. Pluske JR. Morphological and functional changes in the small intestine of the newly weaned pig. In: Piva A, Knudsen KEB, Lindberg JE. Gut environment of pigs. Nottingham: University Press. 2001; p.1-27.

13. Nabuurs MJA. Morphological, structural and functional changes of the small intestine of pigs at weaning. Pig News and Information. 1995;16(3):93N-97N.

14. Budiño FEL, Thomaz MC, Kronka RN, Nakaghi LSO, Tucci FM, Fraga AL, Scandolera AJ, RoblesHuaynate RA. Effect of probiotic and, or prebiotic inclusion in weaned piglet diets on structure and ultrastructure of small intestine. Braz Arch Biol Techn. 2005;48(6):921-929.

15. Gomide Junior MH, Sterzo V, Macari M, Boleli IC. Use of scanning electron microscopy for the evaluation of intestinal epithelium integrity. Rev Soc Bras Zootecn. 2004;3:1500-1505.

16. Scandolera AJ, Thomaz MC, Kronka RN, Fraga AL, Budiño FEL, Robles-Huaynate RA, Ruiz US, Cristani J. Efeitos de fontes protéicas na dieta sobre morfologia intestinal e desenvolvimento pancreático de leitões recém-desmamados. Rev Bras Zootecn. 2005;34(6):2355-2368. 